\title{
Temperature- and humidity-induced changes in alum-treated wood: a qualitative X-ray diffraction study
}

\author{
Caitlin M. A. McQueen ${ }^{1 *}$, Calin C. Steindal' ${ }^{1}$ Olga Narygina ${ }^{2}$ and Susan Braovac ${ }^{1}$
}

\begin{abstract}
Alum-treated wooden artefacts suffer from extreme deterioration, and the stability of these objects and the salts they contain to variations in climate conditions is an important issue. Responses of potassium alum $\left(\mathrm{KAl}_{(}\left(\mathrm{SO}_{4}\right)_{2} \cdot 12 \mathrm{H}_{2} \mathrm{O}\right)$, ammonium alum $\left(\mathrm{NH}_{4} \mathrm{Al}\left(\mathrm{SO}_{4}\right)_{2} \cdot 12 \mathrm{H}_{2} \mathrm{O}\right)$, potassium bisulfate $\left(\mathrm{KHSO}_{4}\right)$ and alum-treated wood to changing temperature and relative humidity $(\mathrm{RH})$ were therefore investigated at the crystalline level using powder X-ray diffraction (XRD). The XRD analysis showed changes in the crystal structures of alum salts that suggest some degree of dehydration starting at $40^{\circ} \mathrm{C}$ at $15 \% \mathrm{RH}$. Rehydration of such dehydrated alum in Oseberg wood samples was still ongoing after 2 years. However, alum salts on their own and in alum-treated wood generally appeared to be stable to most of the changing climate conditions. Conversely, the minor potassium bisulfate component found in some samples was very sensitive to all changes in $\mathrm{RH}$ and temperature, and may even cause changes to the alum component under some conditions. This may be related to the efflorescence of $\mathrm{K}_{9} \mathrm{H}_{7}\left(\mathrm{SO}_{4}\right)_{8} \cdot \mathrm{H}_{2} \mathrm{O}$ crystals seen on some fragments after long-term exposure to high $\mathrm{RH}$. These findings can help to refine $\mathrm{RH}$ and temperature limits for alum-treated objects, and also demonstrate the utility of temperature- and RH-controlled XRD for qualitative monitoring of climate-induced changes in such salt-impregnated materials.
\end{abstract}

Keywords: X-ray diffraction, Temperature, Relative humidity, Potassium alum, Ammonium alum, Potassium bisulfate, Alum-treated wood

\section{Introduction}

From the mid-1800s up until the late 1950s, alum treatment was a commonly used method for conserving waterlogged archaeological wood [1]. This method involved immersing the object in a hot $\left(90{ }^{\circ} \mathrm{C}\right)$ concentrated solution of alum $\left(\mathrm{KAl}\left(\mathrm{SO}_{4}\right)_{2} \cdot 12 \mathrm{H}_{2} \mathrm{O}\right)$. The alum replaced the water in the outer layer of the wood, and the recrystallised salt prevented wood shrinkage as the object dried. This method was most widely used in Scandinavia, where many thousands of wood pieces were thus treated over this 100 year period. This included a large portion of objects from the Oseberg find in Oslo, one of

\footnotetext{
*Correspondence: caitlin.mcqueen@khm.uio.no

${ }^{1}$ Department of Collection Management, Museum of Cultural History,

University of Oslo, Postboks 6762 St. Olavs plass, 0130 Oslo, Norway
}

Full list of author information is available at the end of the article the richest and most comprehensive collections of Viking Age wooden objects in the world.

Drawbacks of the alum treatment have since made its use obsolete. Treated objects are quite brittle, and incomplete penetration of alum can result in the development of cracks and voids due to mechanical strain between alum-rich and alum-poor areas. Alum-treated objects also display high acidity and lose structural integrity over time [2-5]. Today, extensive chemical characterisation of wood from the Oseberg collection has linked extreme degradation of wood polymers to alum treatment and consequent release of sulfuric acid [6-8]. Despite these investigations, questions remain about whether alum itself is stable in its current form in treated wood within reasonable temperature and relative humidity (RH) ranges, which are important to address in order to assess whether it is necessary to remove alum in eventual retreatment as opposed to de-acidification without alum 
removal. Currently, the Viking Ship Museum, where the Oseberg collection is displayed, is a naturally ventilated building that is heated in the winter but not climate-controlled in the summer. Recent climate monitoring measured temperatures up to $26^{\circ} \mathrm{C}$ and $\mathrm{RHs}$ of $35-78 \%$ over the course of a year. ${ }^{1}$ However, in display cases RH is controlled to $45-50 \%$, with seasonal fluctuations of $\pm 10 \%$ considered acceptable.

Some previous studies have looked into the response of alum to changing $\mathrm{RH}$, finding that alum-treated wood is indeed sensitive to such changes [5, 9], although this appears to be due to moisture uptake of the wood and not necessarily alum, which in its pure form does not display significant mass gain or loss for a range of RHs and temperature between 15 and $95 \%$ and $15-40{ }^{\circ} \mathrm{C}$ [4, $10,11]$. However, responses of salts to ambient and artificially-induced climate fluctuation, such as formation of crystalline efflorescence, have been previously observed in alum-treated wood from the collection [11, 12]. In order to further explore such observations, as well as clarify appropriate $\mathrm{RH}$ and temperature limitations for alum-treated objects, we herein expand on the previous studies by investigating $\mathrm{RH}$ - and temperature-induced responses in alum-treated wood at the crystalline level using powder X-ray diffraction (XRD). The following work first presents some preliminary investigations in which we characterised alum-treated Oseberg samples exposed to elevated temperature and $\mathrm{RH}$ and crystalline efflorescence similar to that observed in the previous work. This was followed by use of a climate chamber sample holder to perform more systematic monitoring of temperature- and $\mathrm{RH}$-induced responses in alum and alum-treated wood. Since the previous studies were undertaken, extensive chemical characterisation of alumtreated wood from the Oseberg collection has revealed that they can contain significant amounts of ammonium alum $\left(\mathrm{NH}_{4} \mathrm{Al}\left(\mathrm{SO}_{4}\right)_{2} \cdot 12 \mathrm{H}_{2} \mathrm{O}\right)$ and potassium bisulfate $\left(\mathrm{KHSO}_{4}\right)$ in addition to potassium alum $[8,13]$, and thus these materials are also included in the current study. We explore temperatures and RHs relevant to the museum's annual climate, as well as more extreme $\mathrm{RH}$ and temperature ranges that could be used in accelerated ageing studies.

\section{Materials and methods \\ Samples}

Potassium alum and potassium bisulfate (puriss p.a.>99\%) were purchased from Sigma-Aldrich. Ammonium alum (purum p.a.>99\%) was purchased from

\footnotetext{
${ }^{1}$ From internal, unpublished report Saving Oseberg Phase II Klimarapport Vikingskipshuset 2017 by G. Hjulstad.
}

Honeywell. The sample of fresh birch, FBA-1, had been recently treated with alum in the lab in 2012.

Samples of archaeological wooden artefacts were taken from fragments of two different unreconstructed objects from the Oseberg find, a loom (185) and a simple sled (229), which had been treated with alum but not with any other materials. Their extreme deterioration made it difficult to identify the wood genus used, though examination at lower magnification indicated that they are made of a diffuse porous hardwood, very likely birch (Betula spp.), based on identification of fragments from other objects. These were previously characterised by a range of analytical techniques and found to contain potassium bisulfate as a minor component [8].

Samples were ground into fine powders for the analysis using a mortar and pestle, except for FBA-1, the wood structure of which was in good condition and needed to be powdered by filing.

\section{Alum-treatment}

The alum-treatment, as it was used on the Oseberg finds, involved heating a concentrated solution of alum salts to $90{ }^{\circ} \mathrm{C}$. The waterlogged wood fragments were immersed in the bath for an average of $24 \mathrm{~h}$. The excavation publication states that the concentration of the alum solution was 2 parts alum to 1 part water by weight. However, it also stated that more concentrated baths were prepared, without specifying actual concentrations [14]. It is therefore uncertain which proportion of the objects were actually treated with a 2:1 solution of alum:water.

To prepare the alum-treated sample FBA-1 in the lab, a concentration of 2:1 parts water to potassium alum by weight was used. The sample was immersed in the hot $\left(90^{\circ} \mathrm{C}\right)$ alum bath for $24 \mathrm{~h}$ and was air-dried.

\section{Conditions of preliminary climate experiments}

A fragment from sled 229 (fragment 229-3), had been kept at $75 \% \mathrm{RH}$ and $20^{\circ} \mathrm{C}$ for 2 years, after which small white needle-shaped crystals were observed on the surface. To identify the crystals they were sampled and analysed by XRD under ambient conditions.

In order to assess the effect of drying by mild heating on alum-treated Oseberg wood, samples from three 185 fragments, $185-4,185-5$ and 185-6, were characterised by XRD then heated to $50{ }^{\circ} \mathrm{C}$ in an oven for $24 \mathrm{~h}$. The samples were then returned to ambient conditions and XRD measurements performed immediately, after 2 months and 2 years.

\section{$\mathrm{X}$-ray diffraction}

XRD analysis was carried out using a PANalytical diffractometer Empyrean Series 2 with radiation 
$\mathrm{CuK} \alpha=1.54 \AA$, operating at $45 \mathrm{kV}, 40 \mathrm{~mA}$, equipped with a PIXcel ${ }^{1 \mathrm{D}}$ (Medipix3) detector. HighScore Plus suite was used for data analyses [15]. Crystalline phases were identified using the ICDD-2016 database. Phase quantification was performed using the Rietveld method $[16,17]$, which is a well-established fullpattern fit method for standardless quantitative phase analyses.

Measurements at ambient conditions were performed using a reflection-transmission spinner stage and zero background sample holder, with $2 \theta$ range $8-70^{\circ}$, step size $0.03^{\circ}$ and time per step ranging between 997 and $4997 \mathrm{~s}$.

To investigate the response of various samples to changing temperature and $\mathrm{RH}$ conditions, temperature- and humidity-controlled (TH) measurements were performed using a $\mathrm{CHC}$ plus ${ }^{+}$Cryo and Humidity Chamber with TCU 110 Temperature Control Unit and MHG-32 Modular Humidity Generator, with $2 \theta$ range $8-60^{\circ}$, step size $0.03^{\circ}$ and time per step $997 \mathrm{~s}$. As $\mathrm{RH}$ can be quite variable without climate control and large ranges had been used in previous reports, a range of $15-90 \%$ was explored. Temperatures ranging from room temperature up to $60{ }^{\circ} \mathrm{C}$ were also investigated, the maximum temperature being chosen to be higher than the $50{ }^{\circ} \mathrm{C}$ used in previous artificial ageing experiments and to dry samples prior to some analyses $[5,7$, 8]. The temperature variation was explored at a standard $\mathrm{RH}$ of $50 \%$, as used in climate-controlled display cases, and low RH of $15 \%$, well below the minimum observed in the museum, to favour dehydration. This resulted in the following $\mathrm{TH}$ programs:

(A) Temperature steps: $25,30,35,40,50,60{ }^{\circ} \mathrm{C}$; $\mathrm{RH}=50 \%$.

(B) Temperature steps: $20,25,30,35,40,50,60{ }^{\circ} \mathrm{C}$; $\mathrm{RH}=15 \%$.

(C) $\mathrm{RH}$ steps: $15,30,45,60,75,90,50 \%$; temperature $=25^{\circ} \mathrm{C}$.

The following samples were included in the TH-XRD study: potassium alum, ammonium alum, potassium bisulfate, 50:50 potassium alum to potassium bisulfate by weight (K-alum: $\mathrm{KHSO}_{4}$ ), alum-treated fresh birch (FBA-1) and alum-treated Oseberg wood (229-5). All samples were exposed to all programs, apart from 2295 , which was only exposed to (A) and (C) due to limited amount of sample. One hour equilibration time was allowed at each step before the XRD pattern was collected (which took ca. 2 h $20 \mathrm{~min}$ ). In some cases when small changes were seen, the samples were exposed to the relevant $\mathrm{RH} /$ temperature level for longer periods of time (up to $48 \mathrm{~h}$ ).

\section{Results and discussion}

\section{Crystallographic results from preliminary climate experiments}

In an earlier report, efflorescence of small, white, needleshaped crystals were observed on the surface of alumtreated fragments from object 229 after being subjected to $\mathrm{RH}$ cycling between $30 \%$ and $80 \%$ in $12 \mathrm{~h}$ intervals at $30{ }^{\circ} \mathrm{C}$ for 7 months [11]. Although the sample size of these crystals was too small for conclusive XRD analysis, elemental analyses detected potassium and sulfur and potassium bisulfate was identified in the wood fragments, suggesting that the efflorescence may be related to the potassium bisulfate component. However, we later observed similar crystals on the surface of another fragment, 229-3, from the same object that had been kept at $75 \%$ RH for 2 years. These gave an XRD pattern with several peaks matching a $\mathrm{K}_{9} \mathrm{H}_{7}\left(\mathrm{SO}_{4}\right)_{8} \cdot \mathrm{H}_{2} \mathrm{O}$ reference (Fig. 1). Although the small, thin crystals were not of sufficient quality for a single-crystal study to support this assignment, and other minor peaks were present in the powder pattern, this compound would certainly be consistent with the previous analysis, and could result from the codissolution and recrystallization of $\mathrm{KHSO}_{4}$ with $\mathrm{K}_{2} \mathrm{SO}_{4}$ or K-alum.

Another unanticipated response of alum-treated wood to climate conditions was observed when samples from object 185 were analysed by methods that required drying them beforehand. After mild heating to $50{ }^{\circ} \mathrm{C}$, XRD showed the patterns of the dried samples to be very different to those before heating. As can be seen for 185-5 in Fig. 2, alum peaks disappeared after heating and the XRD pattern contains a broad hump centred around $27^{\circ}$, suggesting the presence of an amorphous phase, which was still present after 2 months. The observed increase in the amorphous content after heating was quantified using the Rietveld method. The XRD pattern prior to heating was used as an external standard for instrument constant estimation (a.k.a. K-factor). Quantification of the increase in amorphous content relative to the sample before heating confirms that the relative amount has not changed over the 2 months, calculated at ca. $98 \%$ for the samples immediately after heating, after 2 weeks and after 2 months. Two years after heating, crystalline alum peaks had reformed, but are accompanied by additional peaks that match a reference for a dehydrated form of alum, $\mathrm{KAl}\left(\mathrm{SO}_{4}\right)_{2} \cdot 6 \mathrm{H}_{2} \mathrm{O}$. Similar observations were made for samples 185-4 and 185-6, indicating that alum was not stable under the drying conditions, undergoing dehydration and taking years to revert back to its original fully hydrated form. Such slow rehydration was surprising, given that previous analysis of alum and alum-treated wood by dynamic vapour sorption showed rehydration of dehydrated alum within a few hours when exposed to 


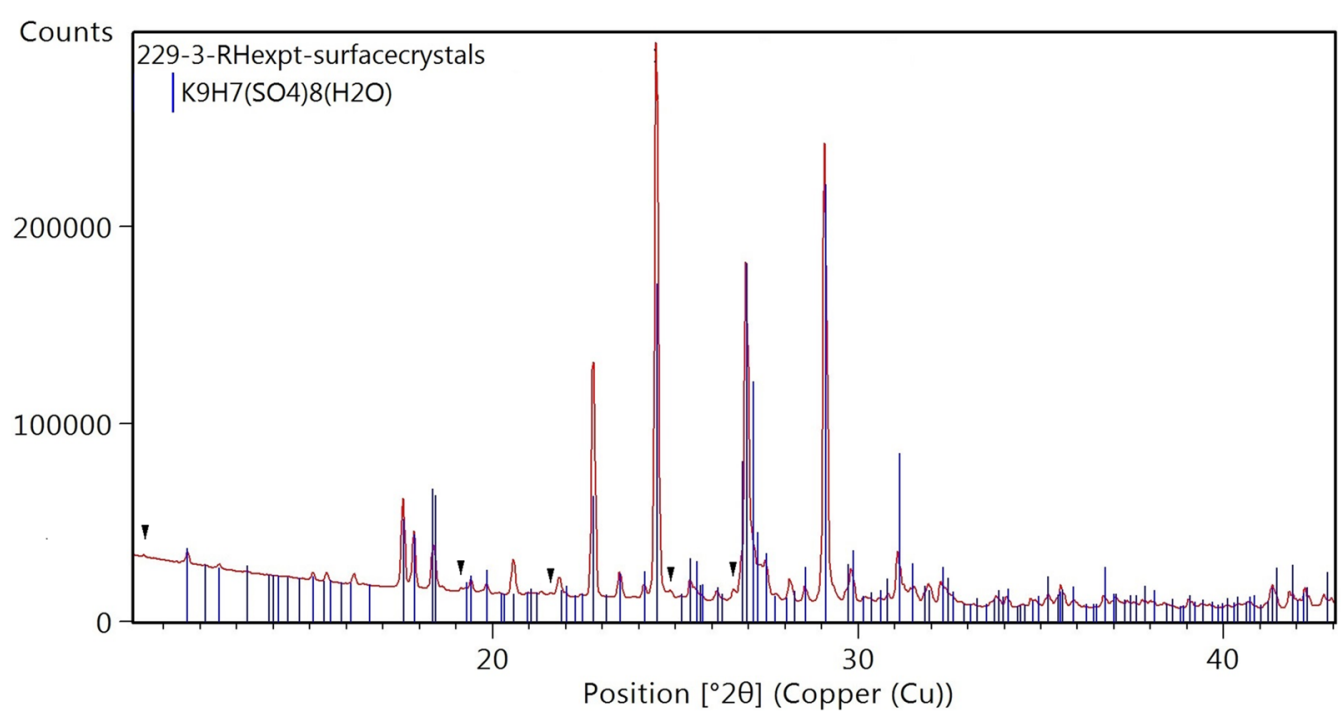

Fig. 1 XRD pattern of crystals on the surface of fragment $229-3$ after 2 years at $75 \% \mathrm{RH}$, with $\mathrm{K}_{9} \mathrm{H}_{7}\left(\mathrm{SO}_{4}\right)_{8} \cdot \mathrm{H}_{2} \mathrm{O}$ reference. Minor peaks not accounted for by the reference pattern are marked with inverted triangles

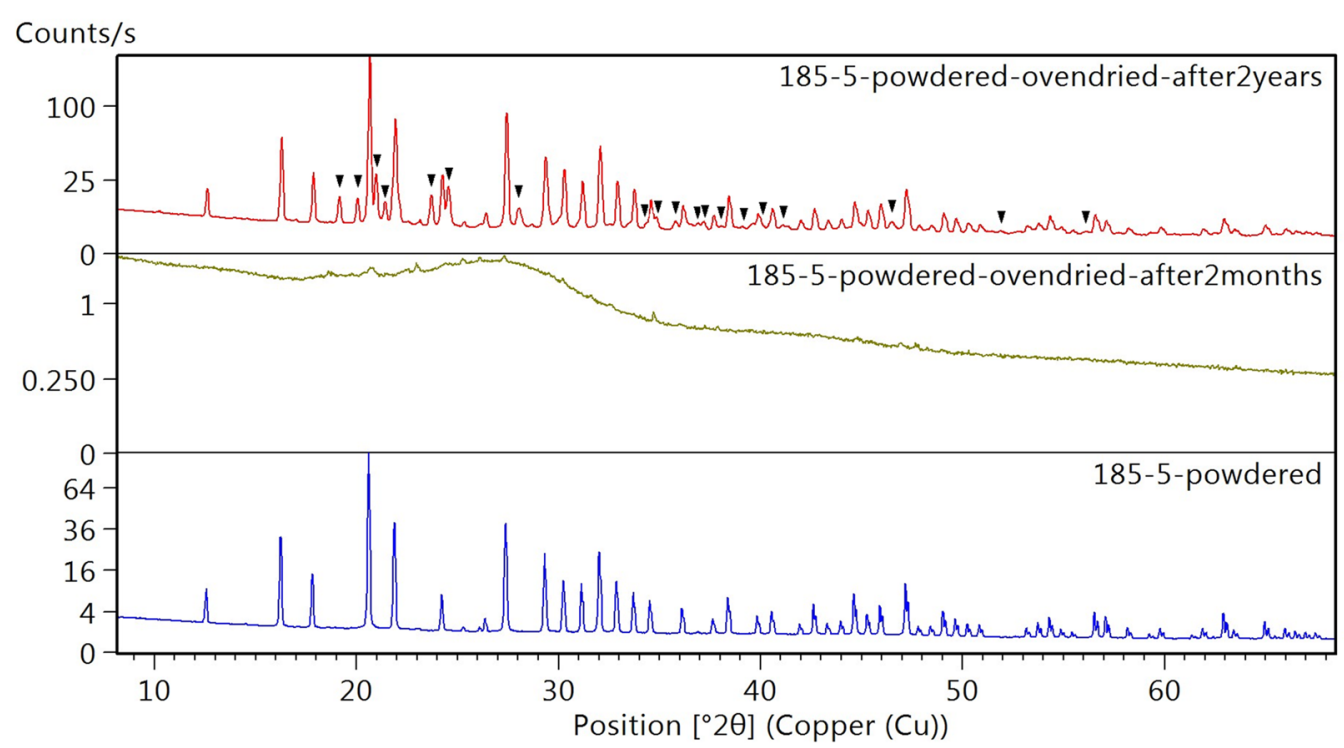

Fig. 2 XRD pattern of powder sample from fragment 185-5 (refined lattice constant for potassium alum, a =12.16561(3), space group Pa-3) and patterns taken 2 months and 2 years after mild heating, showing conversion of alum to an amorphous phase (98\% increase in amorphous contribution), which remains after 2 months. After 2 years crystalline alum peaks have reformed, accompanied by peaks from dehydrated form $\mathrm{KAl}\left(\mathrm{SO}_{4}\right)_{2} \cdot 6 \mathrm{H}_{2} \mathrm{O}$ (marked with inverted triangles)

$30-40 \% \mathrm{RH}$ at $30{ }^{\circ} \mathrm{C}[10]$. This suggests that the rate of this process is greatly reduced under ambient conditions, which in our lab are temperatures around $20{ }^{\circ} \mathrm{C}$ with large variations in $\mathrm{RH}$.

These observations, as well as general concerns about the stability of alum-treated wood, prompted us to design an XRD study to investigate climate-induced changes in alum-treated wood in a more systematic manner via stepwise variations in $\mathrm{RH}$ and temperature.

Temperature- and humidity-controlled XRD experiments Potassium and ammonium alum

Both potassium and ammonium forms of alum remained unchanged throughout temperature cycle (A) at RH 50\%. 


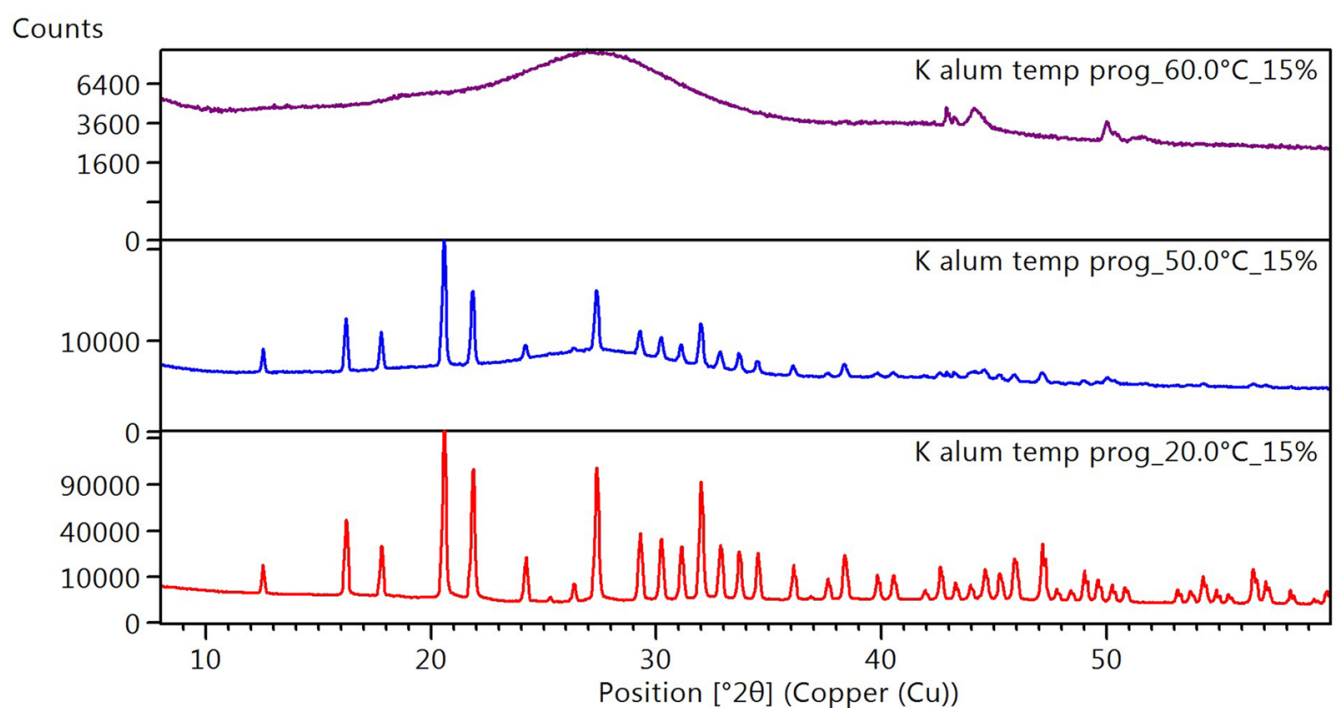

Fig. 3 XRD patterns of potassium alum at $20^{\circ} \mathrm{C}, 50^{\circ} \mathrm{C}$ and $60^{\circ} \mathrm{C}$ during temperature cycle (B). Intensity in square root scale

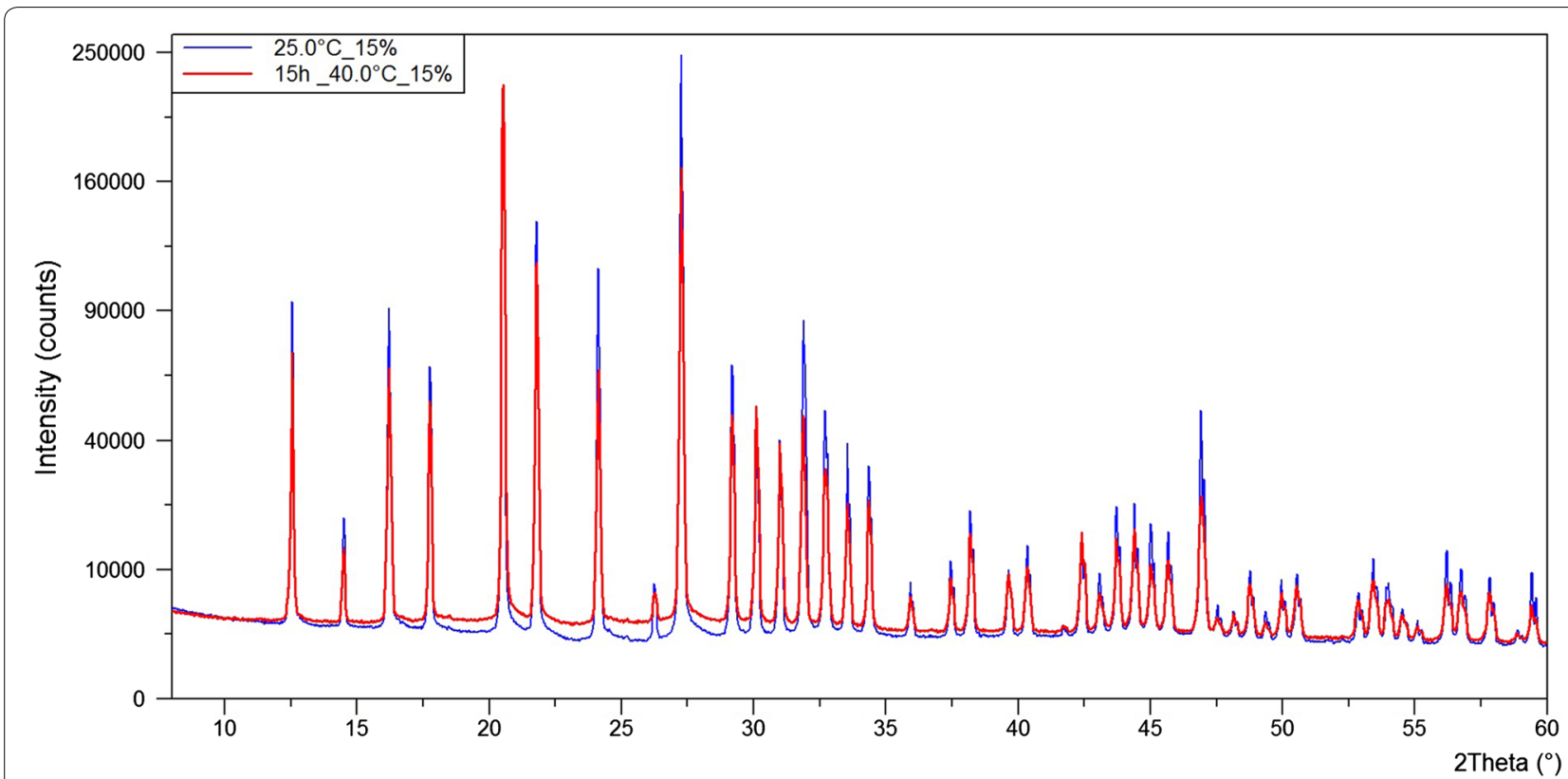

Fig. 4 XRD pattern of ammonium alum after $15 \mathrm{~h}$ at $40^{\circ} \mathrm{C}$, compared to pattern at $25^{\circ} \mathrm{C}$ (refined lattice constant for alum, a $=12.24435(4)$, space group Pa-3), showing an increase in amorphous content of ca. 14\%. For equivalent patterns of potassium alum the increase in amorphous content was ca. $23 \%$ at $40{ }^{\circ} \mathrm{C}$ relative to $25^{\circ} \mathrm{C}$ (refined lattice constant for alum, $\mathrm{a}=12.16551$ (5), space group Pa-3). Intensity in square root scale

However, when the $\mathrm{RH}$ was reduced to $15 \%$ in cycle (B), clear changes are seen at $50^{\circ} \mathrm{C}$ (Fig. 3). Reduction in crystalline peak intensities accompanied by growth of a broad hump centred around $27^{\circ}$ indicates formation of amorphous phases. At $60{ }^{\circ} \mathrm{C}$, the original peaks of crystalline alum have completely disappeared. Small changes were also seen at $40{ }^{\circ} \mathrm{C}$, and after the exposure times to this temperature were extended to $15 \mathrm{~h}$, repeat measurements showed clear increases in amorphous content and reduction of peak intensities (Fig. 4). Although the increase in amorphous content looks small, Rietveld quantification suggests this corresponds to ca. $14 \%$ and $23 \%$ more amorphous contribution for ammonium alum and potassium alum, respectively, relative to the patterns at $25^{\circ} \mathrm{C}$. 


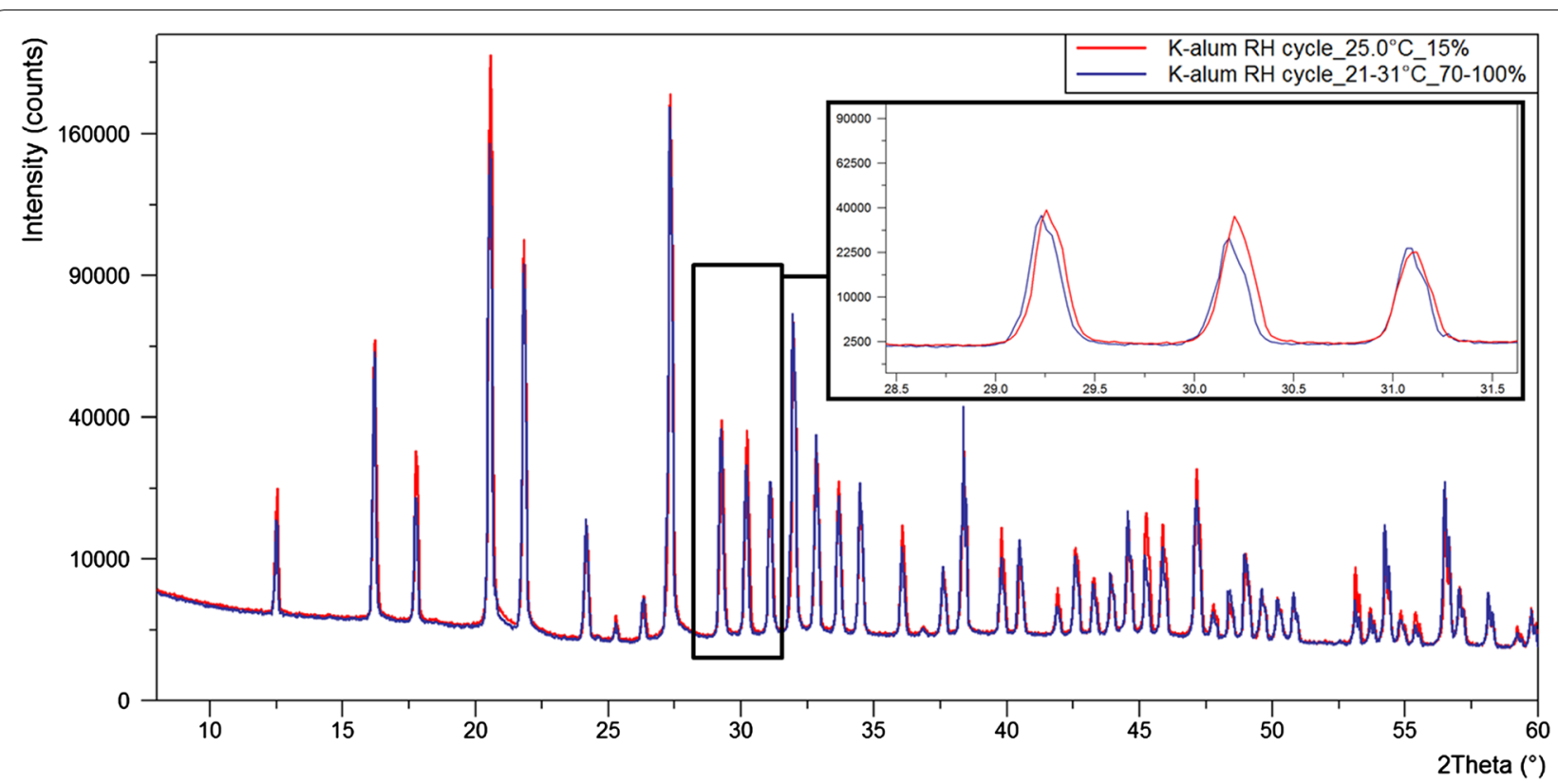

Fig. 5 XRD patterns of potassium alum during RH cycle (C) at 15\% RH and high unstable RH, with close up to show slight shifts. Intensity in square root scale

However, no changes were seen for the lower temperatures at $15 \% \mathrm{RH}$ after $15 \mathrm{~h}$ of exposure.

Though previous studies of thermal responses of alums mainly focus on overall dehydration completed at high temperatures $\left(>100^{\circ} \mathrm{C}\right)$ [18-20], one study of potassium alum at lower temperatures notes transition to a similar amorphous phase beginning at $75^{\circ} \mathrm{C}$ at an average $\mathrm{RH}$ of ca. $60 \%$, which is attributed to partial dehydration (five to six water molecules) [21]. The present study indicates that such amorphous phases begin to form at as low temperatures as $40{ }^{\circ} \mathrm{C}$ when $\mathrm{RH}$ is controlled at $15 \%$. We note here that, when Häggström et al. exposed potassium alum to $15 \% \mathrm{RH}$ and $40{ }^{\circ} \mathrm{C}$, they observed minimal mass loss $(<1 \mathrm{wt} \%)$ [4]. The amount of amorphous content in the present experiment is significant under the same conditions, according to the quantification results, and if this does indeed correspond to loss of at least five water molecules from ca. $23 \%$ of the potassium alum sample, this should result in an overall mass loss of around $4 \mathrm{wt} \%$. However, this assumes that loss of water from the crystal structure is the same as loss of water from the total sample, which may not be the case if water remains adsorbed on the alum powder or sample holder. Furthermore, the XRD experiments required finely ground powders and therefore the grains have a large relative surface area that would make them more susceptible to dehydration. In any case, it seems that the degree of dehydration causing the observed crystalline changes under these conditions may not be detected as significant mass loss, but nonetheless implies physical transformation of the sample.

During RH cycle $(\mathrm{C})$, minimal changes in the alums were seen between RH $15-75 \%$. This is consistent with literature on their RH-related phase transitions at ambient temperatures; phase transitions are only noted at very low $\mathrm{RHs}$ of $<10 \%$, to form the corresponding hexahydrates [22]. Our instrument had difficulty reaching a stable $\mathrm{RH}$ of $90 \%$ due to insufficient flow and quality of supplied compressed air, and therefore the conditions during these measurements actually fluctuated between 21 and $31{ }^{\circ} \mathrm{C}$ and $70-100 \% \mathrm{RH}$. We refer to these conditions as "unstable high RH". Slight but clear shifts and change in intensity of peaks were seen for K-alum under the unstable high RH conditions (Fig. 5). This is perhaps due to sample displacement caused by caking, which can occur when crystal surfaces become damp [23], as the finely ground powder was observed have bound together to some extent after exposure to high RH.

\section{Potassium bisulfate and alum}

For pure potassium bisulfate, non-uniform changes in peak intensities and slight position shifts were seen throughout all cycles. This indicates that the crystal structure of this compound is very sensitive to changing $\mathrm{RH}$ and temperature conditions. Although the stable phase of potassium bisulfate is anhydrous [23], the salt is quite hygroscopic and the observed changes could be perhaps induced by the partial presence of water in the 


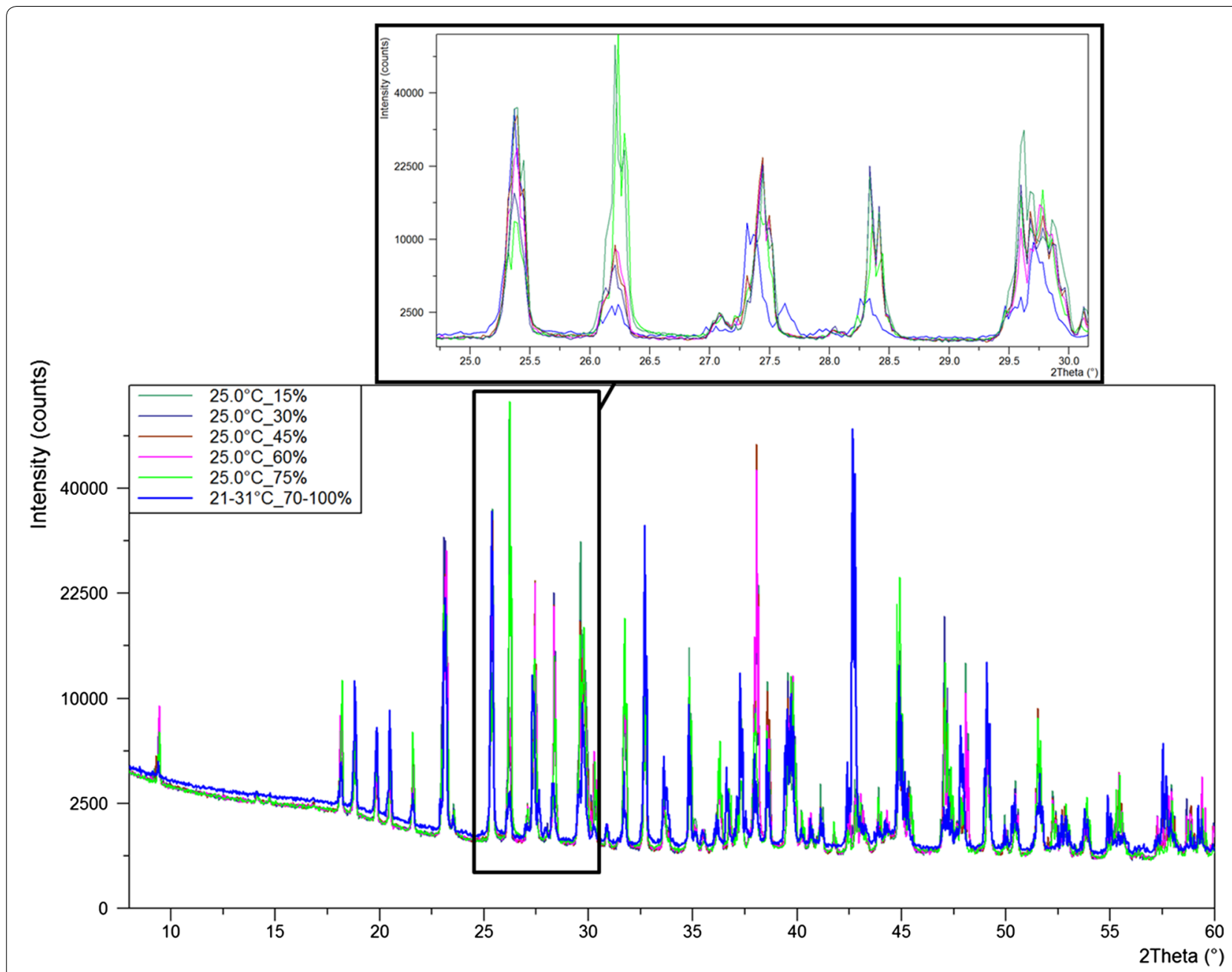

Fig. 6 XRD patterns of potassium bisulfate during RH cycle (C) with close up to show changes more clearly. Intensity in square root scale

crystal structure. This is most pronounced at high unstable RH (Fig. 6), which is unsurprising, as the deliquescence point of potassium bisulfate is reported at $86 \% \mathrm{RH}$ at $15^{\circ} \mathrm{C}$ [23].

When mixed with potassium alum in the K-alum: $\mathrm{KHSO}_{4}$ mixture, the temperature-induced changes in the bisulfate structure were not so obvious, although the conversion of K-alum to the amorphous phase discussed above is seen. However, changing intensities and peak positions are seen during the $\mathrm{RH}$ cycle (C). Notably, unstable high RH causes almost complete disappearance of many of the bisulfate peaks (Fig. 7), and when the RH was dropped back to $50 \%$ in the final step, the bisulfate pattern reappears with two peaks having unusually strong relative intensities, which was not seen for pure potassium bisulfate. This suggests deliquescence of the bisulfate at high $\mathrm{RH}$ followed by recrystallisation to give a very strong preferred orientation in the presence of alum. Large changes in all other peak intensities are seen, as well as some shifts, indicating that the process also influenced the alum crystals, which could indicate that they also recrystallised to some degree. Furthermore, the presence of some new peaks indicates the formation of a new phase. The list of many possible matching reference patterns included several phases made up of stoichiometric combinations of $\mathrm{KHSO}_{4}$ and $\mathrm{K}_{2} \mathrm{SO}_{4}$, such as the $\mathrm{K}_{9} \mathrm{H}_{7}\left(\mathrm{SO}_{4}\right)_{8} \cdot \mathrm{H}_{2} \mathrm{O}$ that matched the efflorescence described in the preliminary experiments, but the peaks were too small to confidently assign to any of the suggested phases. Therefore we cannot say what this phase is, but it could result from a reaction between the bisulfate and the alum. Perhaps such a reaction might ultimately be linked to the efflorescence observed on alum-treated Oseberg fragments after the long-term RH experiments. 


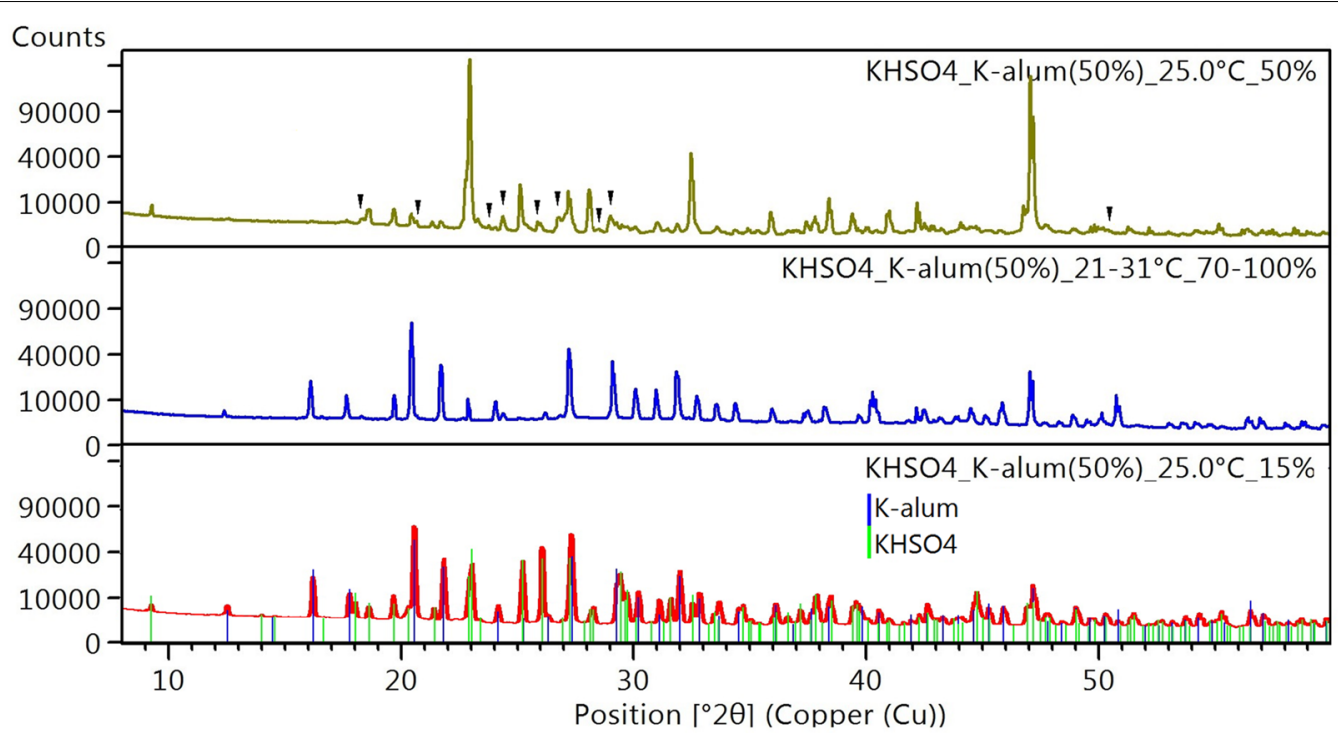

Fig. 7 K-alum: $\mathrm{KHSO}_{4}$ during $\mathrm{RH}$ cycle (C), intensity in square root scale. At initial $\mathrm{RH}$ of $15 \%$ with $\mathrm{K}$-alum and $\mathrm{KHSO}_{4}$ references are also shown. At unstable high $\mathrm{RH}$ many $\mathrm{KHSO}_{4}$ peaks disappear. At the final 50\% $\mathrm{RH} \mathrm{KHSO}_{4}$ peaks have reappeared with drastic changes in relative intensities, and inverted triangles mark new peaks not accounted for by $\mathrm{K}$-alum and $\mathrm{KHSO}_{4}$ references

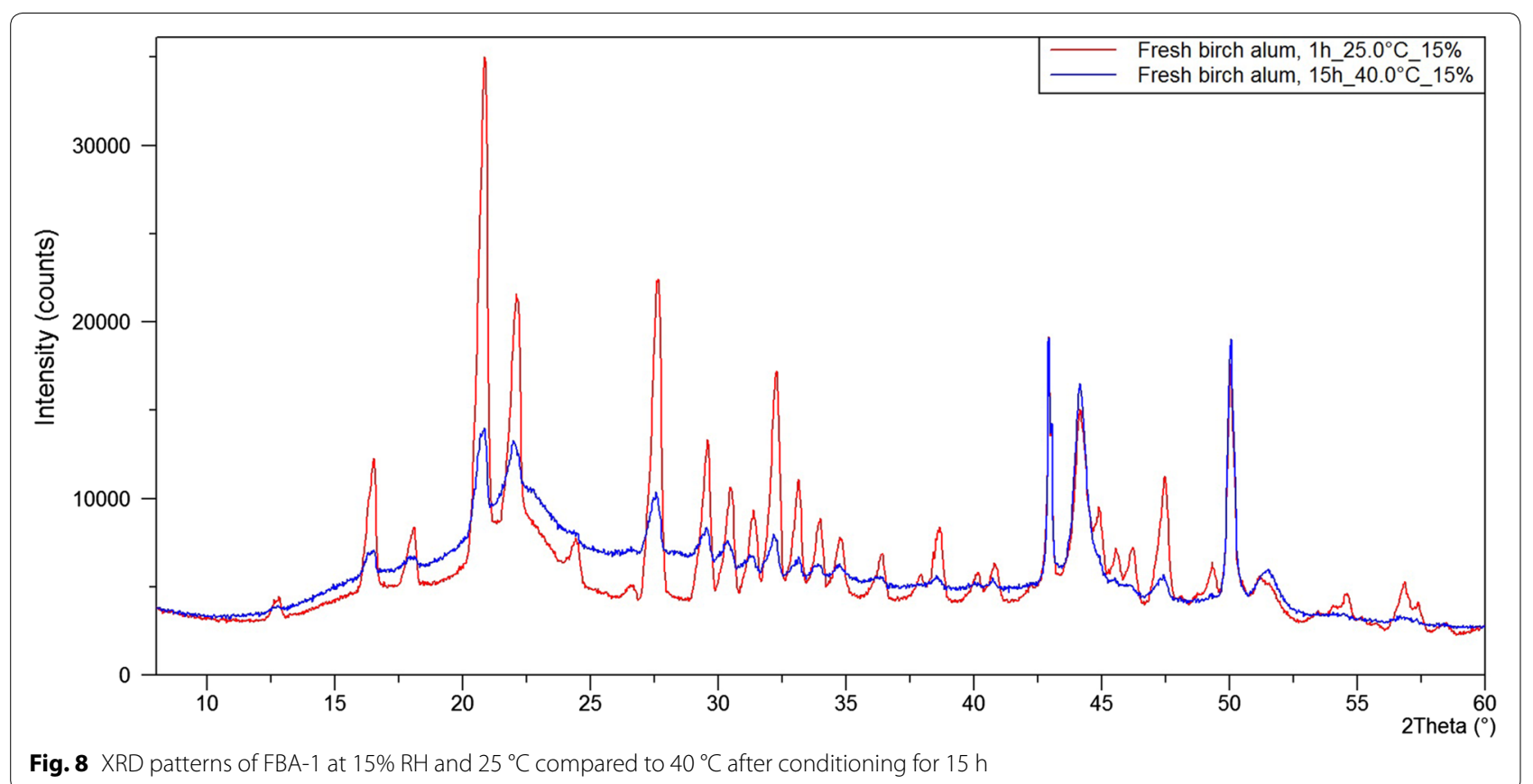

\section{Alum-treated wood samples}

For the fresh birch sample, FBA-1, the potassium alum component responded similarly to the pure alum during the temperature cycles (A) and (B): little change was observed at $50 \% \mathrm{RH}$, but at $15 \% \mathrm{RH}$ increase in amorphous content and reduction of peak intensities was observed at $40{ }^{\circ} \mathrm{C}$, which was more pronounced after
15 h (Fig. 8). Peaks from the sample holder (at ca. 43, 44,50 and $51^{\circ}$ ) can also be seen in these patterns, presumably because it packed less densely than the other samples. Unlike for the pure alum, however, minimal change in peak intensities was observed during the $\mathrm{RH}$ cycle $(\mathrm{C})$ at unstable high $\mathrm{RH}$. This may be due to the hygroscopic nature of the wood, which could prevent the 


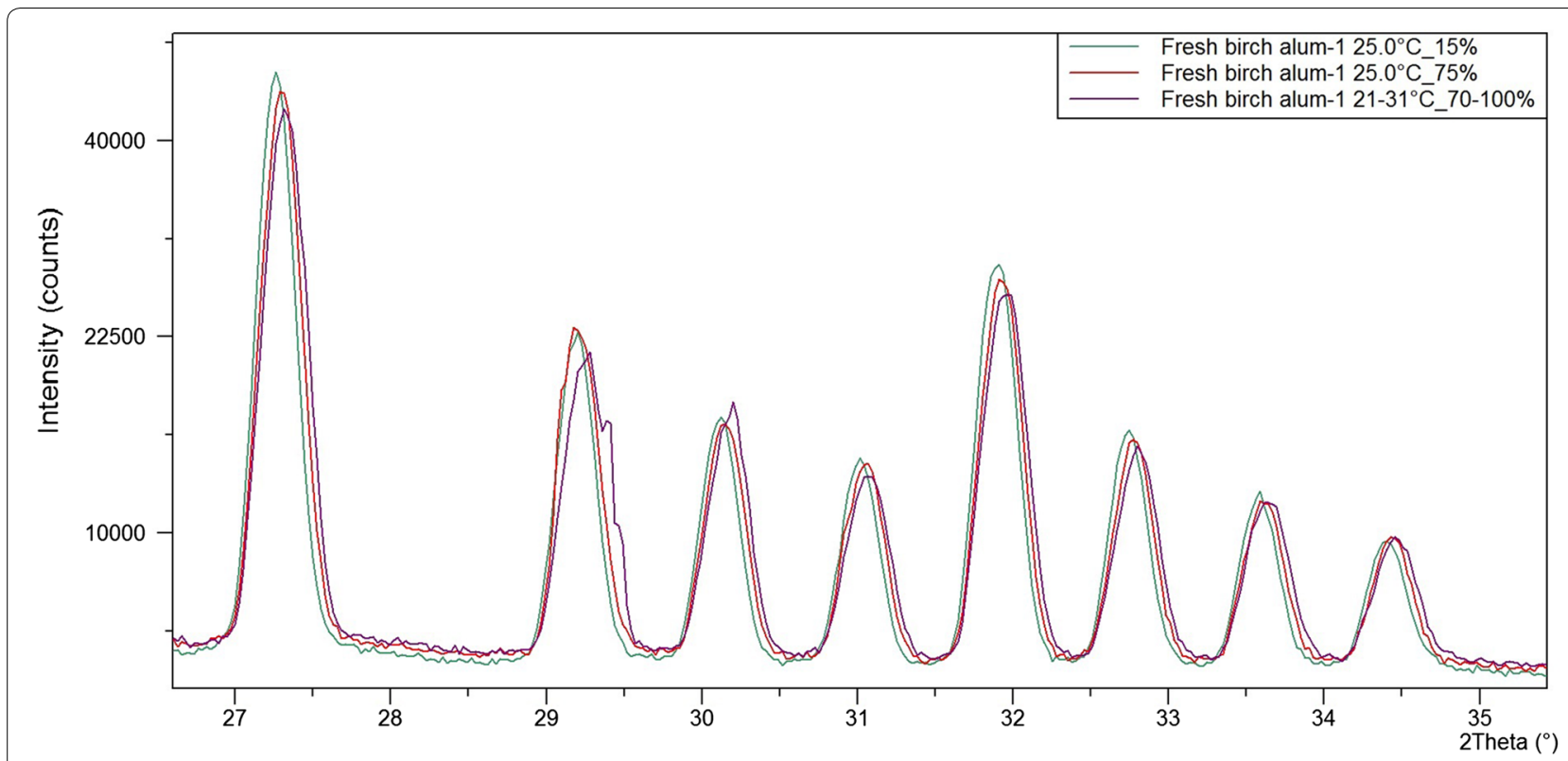

Fig. 9 XRD patterns of FBA-1 at low and high RH, showing uniform shifts. Intensity in square root scale

moisture-induced caking seen in the pure salt. This could also result in sample swelling, which could explain small uniform shifts seen at 75\% and unstable high RH (Fig. 9).

The archaeological sample from Oseberg, 229-5, also showed little change during cycle (A), at least for the alum peaks. Changes in the minor peaks were more difficult to assess due to their low relative intensities. However, during $\mathrm{RH}$ cycle $(\mathrm{C})$, high unstable $\mathrm{RH}$ caused several minor peaks to clearly diminish in intensity, all of which appear to be potassium bisulfate peaks (Fig. 10). Upon reduction of RH back to $50 \%$ in the final step, these peaks reappear with clear changes in intensities and some slight shifts in positions. Some changes in the peak intensities are also seen for the alum peaks. This indicates that the potassium bisulfate in this sample is the most unstable component under these conditions, and could suggest that its deliquescence and recrystallisation influences the crystal structure of alum. This is similar to the observations made for the $\mathrm{K}$-alum: $\mathrm{KHSO}_{4}$ mixture, although in this case the relative intensities of potassium bisulfate were much lower and therefore the changes more subtle. The formation of a new phase was also not apparent in this case, although even in the 50:50 mix the new peaks formed after the RH cycle were very small, and therefore we might expect any such phase in the 229-5 sample to be below the limit of detection.

Overall, in the alum-treated wood, alum responds to temperature similarly to the pure alums: clear changes in the crystal structure of alum begin at $40{ }^{\circ} \mathrm{C}$ at $15 \% \mathrm{RH}$. Otherwise alum appeared to remain unchanged within the temperature and $\mathrm{RH}$ ranges used. This is generally consistent with the previous studies; in their dynamic vapour sorption experiments Mortensen and Taube [10] observed mass loss at $0-10 \% \mathrm{RH}$ at $30{ }^{\circ} \mathrm{C}$ for both pure potassium alum and alum-treated Oseberg wood, but otherwise noted the mass of hydrated alum was almost constant up to $95 \% \mathrm{RH}$. However, they comment that in the experiments performed by Häggström et al. [4], the combination of $40{ }^{\circ} \mathrm{C}$ and $15 \% \mathrm{RH}$ must be close to the dehydration point of alum, although significant mass loss was not observed. The present experiments confirm that this is indeed the case for both alum and alum-treated wood. However, potassium bisulfate, which was found as a minor component of several alum-treated wood samples from Oseberg, may have a destabilising effect on alum when exposed to high $\mathrm{RH}$ conditions.

\section{Conclusions}

The present study demonstrates that XRD is a useful and sensitive tool for monitoring climate-induced changes in crystalline compounds found in alum-treated wood. Changes in the crystal structure of potassium alum that may not necessarily be detected as mass loss were apparent in the XRD patterns under the same conditions after short periods of time.

From the results we can say that crystal structure of alum appears stable at temperatures up to $35{ }^{\circ} \mathrm{C}$ at $15 \%$ $\mathrm{RH}$, up to $60{ }^{\circ} \mathrm{C}$ at $50 \% \mathrm{RH}$, and under changing $\mathrm{RHs}$ between 15 and $75 \%$ at $25{ }^{\circ} \mathrm{C}$. At temperatures above these limits, thermally-induced alum dehydration was 


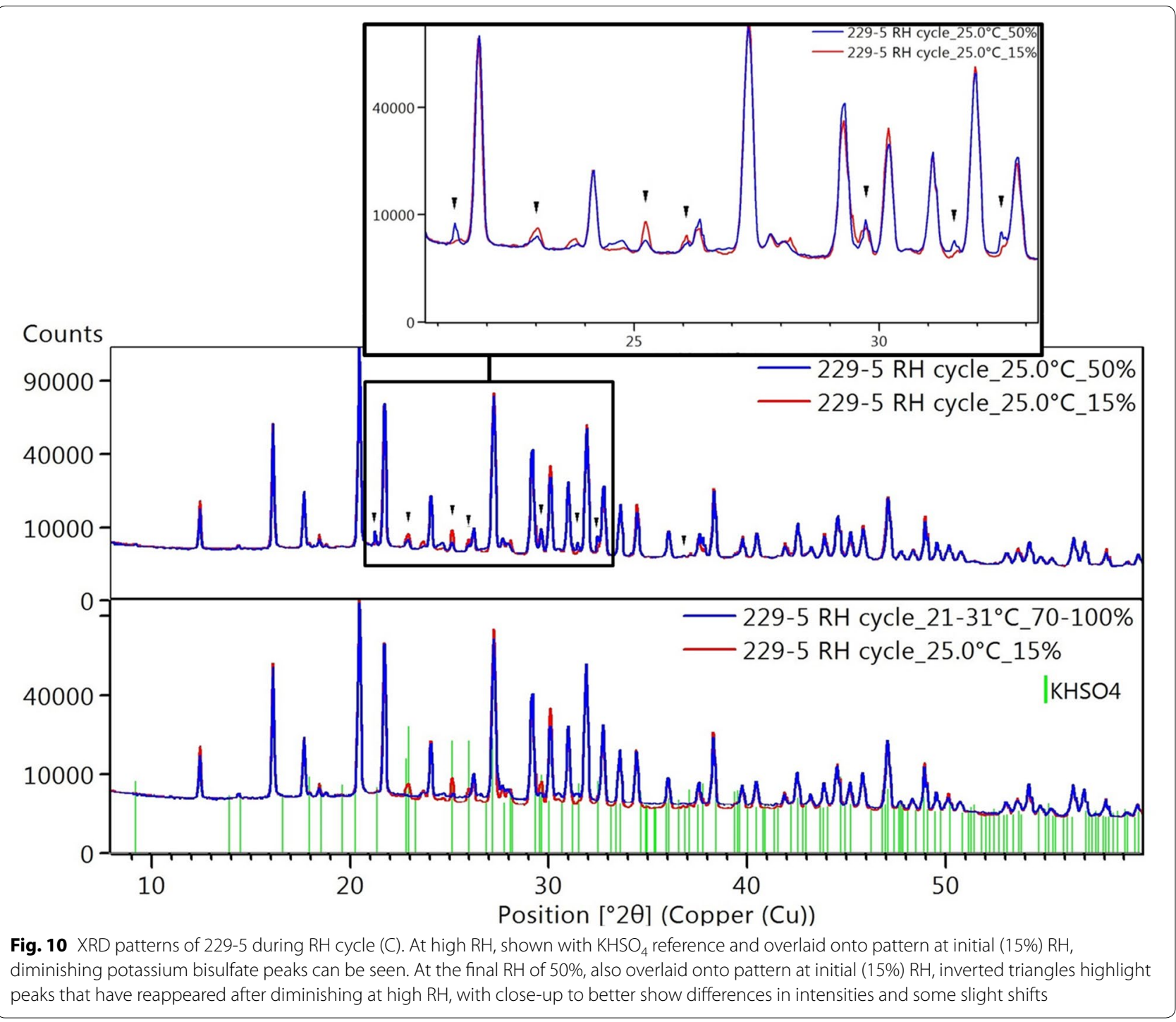

observed that could take years to reverse under ambient conditions.

However, potassium bisulfate, which was found as a minor component of several alum-treated wood samples from Oseberg, was very sensitive to all changes in $\mathrm{RH}$ and temperature. This compound deliquesces at high $\mathrm{RH}$, and, in mixtures with potassium alum, this may also influence the alum structure. Possible reaction between potassium alum and potassium bisulfate might ultimately be linked to $\mathrm{K}_{9} \mathrm{H}_{7}\left(\mathrm{SO}_{4}\right)_{8} \cdot \mathrm{H}_{2} \mathrm{O}$ crystals observed on alum-treated Oseberg fragments after long-term $\mathrm{RH}$ experiments.

These results suggest that, under the normal museum conditions, the crystal structure of alum should remain unchanged, and especially in display cases controlled to $50 \% \mathrm{RH}$ alum is stable well above ambient summer temperatures. However, if accelerated ageing experiments venture outside the above-mentioned temperature and $\mathrm{RH}$ ranges, changes in the alum structure should be expected. Furthermore, the potassium bisulfate by-product of alum-treatment is unstable even to minor changes in climate conditions as well as decreasing the stability of alum, and should be removed from or neutralised in alum-treated objects where possible. This study focusses on crystalline salts, and thereby only partially assesses the overall stability of alum-treated wood. How prone the wood component is to degradation in the continued presence of alum is a key part of determining if alum itself must be removed. This is not readily observed in shortterm experiments and thus remains unclear despite the several previous studies. Ongoing investigations involve longer-term experiments assessing the chemical stability of wood to the continued presence of alum and the acidic by-products of alum-treatment. 


\section{Authors' contributions}

CM collected artefact samples with the help of SB. SB performed alum treatment in the lab and the $\mathrm{RH}$ experiment on fragment 229-3. CM performed heating and ambient XRD analysis on the 185 samples. CM and CS designed and performed the TH-XRD experiments. ON performed amorphous phase quantification and advised on interpretation of XRD data. CM wrote the manuscript and all authors reviewed and edited it. All authors read and approved the final manuscript.

\section{Author details}

1 Department of Collection Management, Museum of Cultural History, University of Oslo, Postboks 6762 St. Olavs plass, 0130 Oslo, Norway. ${ }^{2}$ Malvern PanaIytical, A Division of Spectris Australia Pty Ltd, Unit 24/31 Governor Macquarie Drive, Chipping Norton, Sydney, NSW 2170, Australia.

\section{Acknowledgements}

The authors would like to thank Dr. David Wragg for assistance with interpretation of XRD data and Dr. Hartmut Kutzke for contributions to scientific discussions.

\section{Competing interests}

The authors declare that they have no competing interests.

\section{Availability of data and materials}

The datasets used and/or analysed during the current study are available from the corresponding author on reasonable request.

\section{Funding}

This work was carried out as part of the Saving Oseberg project, funded by the Norwegian Ministry of Education and Research and the University of Oslo.

\section{Publisher's Note}

Springer Nature remains neutral with regard to jurisdictional claims in published maps and institutional affiliations.

Received: 28 September 2018 Accepted: 19 November 2018 Published online: 23 November 2018

\section{References}

1. Unger A, Schniewind AP, Unger W. Conservation of wood artifacts: a handbook. Berlin: Springer-Verlag; 2001.

2. Brorson Christensen B. The conservation of waterlogged wood in the National Museum of Denmark. Copenhagen: National Museum of Denmark; 1970

3. Hoffmann P, Schwab E, Bonde N. Report on strength tests performed on wood samples from the Gokstad Ship and boats, and from the Oseberg finds complex, and some observations on strakes from the Gokstad, Oseberg and Tune ships. In: Bøe A, editor. Vikingskipsseminaret. Oslo: University of Oslo; 2002. p. 71-85.

4. Häggström C, Lindahl K, Sahlstedt M, Sandström T, Wikstad E. Alumtreated archaeological wood: Characterization and re-conservation. Stockholm: Swedish National Heritage Board; 2013.

5. Braovac S. Alum-treated wood: material characterisation: a case study of the Oseberg finds, Doctoral thesis, The Royal Danish Academy of Fine Arts - Schools of Architecture, Design and Conservation; 2015.
6. Braovac S, Kutzke $H$. The presence of sulfuric acid in alum-conserved wood-Origin and consequences. J Cult Herit. 2012;13(3, Supplement):S203-8.

7. Braovac S, Tamburini D, Łucejko JJ, McQueen C, Kutzke H, Colombini MP. Chemical analyses of extremely degraded wood using analytical pyrolysis and inductively coupled plasma atomic emission spectroscopy. Microchem J. 2016:124:368-79.

8. McQueen CMA, Tamburini D, Łucejko JJ, Braovac S, Gambineri F, Modugno $F$, et al. New insights into the degradation processes and influence of the conservation treatment in alum-treated wood from the Oseberg collection. Microchem J. 2017;132:119-29.

9. Hutchings J. The properties of Alum. In: Strætkvern K, Huisman DJ, editors. Proceedings of the 10th ICOM Group on wet organic archaeological materials. Amsterdam. Amersfoort: Rijksdienst voor Archeologie, Cultuurlandschap en Monumenten; 2007. p. 589-614.

10. Mortensen MN, Taube M. Climate dependent degradation processes in conserved archaeological wood. In: Williams E, Hocker E, editors. Proceedings of the 13th ICOM-CC wet organic archaeological materials conference. Florence, Italy: ICOM-CC; 2016. p. 169-75.

11. Mortensen MN, Chaumat G, Gambineri F, Kutzke H, Łucejko JJ, McQueen CMA, et al. Climatically induced degradation processes in conserved archaeological wood studied by time-lapse photography. Stud Conserv. 2018;1:1. https://doi.org/10.1080/00393630.2018.1490103.

12. Rosenqvist AM, editor The Oseberg Find, its conservation and present state. In: Colloque sur l'altération du bois-Symposium on the weathering of wood 1969; Ludwigsburg, Allemagne/Germany: ICOMOS, International Council of Monuments and Sites; 1972.

13. Łucejko JJ, La Nasa J, McQueen CMA, Braovac S, Colombini MP, Modugno F. Protective effect of linseed oil varnish on archaeological wood treated with alum. Microchem J. 2018;139:50-61.

14. Brøgger AW, Falk HJ, Schetelig H. Osebergfundet: 1. Oslo: Distribuert ved Universitetets Oldsaksamling; 1917.

15. Degen T, Sadki M, Bron E, König U, Nénert G. The HighScore suite. Powder Diffr. 2014;29(S2):S13-8.

16. Rietveld HM. Line profiles of neutron powder-diffraction peaks forstructure refinement. Acta Crystallogr. 1967;22:151-2.

17. Rietveld HM. A profile refinement method for nuclear and magneticstruc tures. J Appl Crystallogr. 1969;2:65-71.

18. Wojciechowska R, Wojciechowski W, Kamiński J. Thermal decompositions of ammonium and potassium alums. J Therm Anal. 1988;33(2):503-9.

19. Apte NG, Kiran E, Chernosky JV. Thermal decomposition of aluminiumbearing compounds. J Therm Anal. 1988;34(4):975-81.

20. Földvári M. Handbook of thermogravimetric system of minerals and its use in geological practice. Budapest: Geological Institute of Hungary; 2011.

21. Kishimura $H$, Imasu Y, Matsumoto $H$. Thermal dehydration of potash alum studied by Raman spectroscopy and X-ray diffraction analysis. Mater Chem Phys. 2015;149(Supplement C):99-104.

22. Waller R. Temperature- and humidity-sensitive mineralogical and petrological specimens. In: Howie FM, editor. The care and conservation of geological material: minerals, rocks, meteorites and lunar finds. Oxford: Butterworth-Heinemann Ltd; 1992. p. 25-50.

23. Mullin JW. Crystallizer design and operation. Crystallization. 4th ed. Oxford: Butterworth-Heinemann; 2001. p. 403-7. 